\title{
Prevalence updates of substance use among Egyptian adolescents
}

\author{
Menan Rabie ${ }^{1,2}$, Nermin M. Shaker ${ }^{1,2^{*}}$ (D) Eman Gaber ${ }^{1}$, Mahmoud El-Habiby ${ }^{2}$, Dalia Ismail ${ }^{1}$, Maha El-Gaafary ${ }^{2}$, \\ Amina Lotfy ${ }^{1}$, Noha Sabry ${ }^{1,3}$, Wael Khafagy ${ }^{1}$ and Richard Muscat ${ }^{4}$
}

\begin{abstract}
Background: The problem of substance use is becoming one of the most serious and rapidly growing phenomena all over the world. Efficient and well-designed prevalence studies for mental illnesses including substance use problems need to be regularly updated, in order to rearrange the prevention and management plans on a scientific basis. The aim of the study is to detect the prevalence of substance use and dependence among secondary school students, as they are one of the high-risk populations for drug use, targeting a representative sample of 10,648 of students.

Results: The most commonly used substance was nicotine during lifetime (9\%), last 12 months (4.9\%), and last month (2.4\%). After the exclusion of nicotine, benzodiazepines was the commonest substance abused (5.1\%) followed by alcohol (3.3\%) and organic solvents (3.1\%). The most commonly used during the last 12 months was alcohol (2.9\%) followed by organic solvents (2.7\%) and cannabis (2.6\%). The prevalence of the regular use of any substance was 1.5\%, while the prevalence of the dependence syndrome was $0.9 \%$ (excluding nicotine dependence). The prevalence of intake, regular use, and dependence were all higher among males.

Conclusion: The results of this study attract attention towards the substance abuse problem among adolescents in Egypt. Tobacco is the most commonly used substance followed by benzodiazepines which seemed to be used on a regular basis. Alcohol, organic solvents, and cannabis are also commonly used. Preventive services should be directed towards youth to combat these phenomena.
\end{abstract}

Keywords: Prevalence, Substance use, Dependence, Secondary school students, Adolescents

\section{Background}

Adolescent substance use and misuse are serious issues that contribute to significant medical, psychological, and legal consequences later in life [1]. In 2015, nearly half of the US high school seniors admitted using an illicit drug (excluding alcohol or tobacco) in their lifetime. Twenty-one percent of grade 8 students and $58 \%$ of grade 12 students reported having consumed alcohol [2]. Cannabis has been the most commonly used by adolescents, and its rates are increasing significantly since 1991. Substance use disorder rates among adolescents can be less straightforward than use statistics, as diagnostic criteria and differences in shared nomenclature

\footnotetext{
* Correspondence: mostafabulmagd@hotmail.com

${ }^{1}$ General Secretariat of Mental Health and Addiction Treatment (GSMHAT), Ministry of Health $(\mathrm{MOH})$, Cairo, Egypt

${ }^{2}$ Faculty of Medicine, Ain Shams University, Cairo, Egypt

Full list of author information is available at the end of the article
}

can make large-scale tracking of diagnosis difficult, especially since adolescents are often diagnosed using dependence and problematic use criteria developed for an adult population. The overall prevalence of alcohol and drug disorders between the ages of 12 and 17 has decreased since 2002 till 2016 from 6 to 3\% [3].

A few decades ago, in Egypt, a series of epidemiological studies on psychoactive drug use were conducted. Those concerned with secondary school students revealed $5.05 \%$ for the use of cannabis and $0.84 \%$ for the use of opium. In most studies, the majority of the substance users were males, e.g., one of the studies found that $8.79 \%$ of male university students used cannabis, compared to $0.09 \%$ of female students; meanwhile, the percentage of using sedatives was $8.36 \%$ for male and $5.97 \%$ for female students [4]. The age at onset of substance use ranged between 17 and 28 years old [4-9]. 
Since 1996, the General Secretariat of Mental Health and Addiction Treatment (GSMHAT), Ministry Of Health $(\mathrm{MOH})$, Egypt, has been releasing reports of "The National Research of Addiction, Egypt" to study the substance abuse problem in Egypt. The rates of substance use are increasing markedly with time. The group of young adults was the most represented age group among substance users, i.e., the most vulnerable age group due to the characteristic problems of late adolescence/young adulthood and the peer influence and pressure, in addition to family disruption and family history of substance use [10].

Sporadic studies were performed in Egypt governorates and stated the frequencies and percentages of substance use among young people. However, the samples of these studies were not representative of the general population. In Cairo, Sadek et al. [11] found that the percentage of female secondary school students who smoked cigarettes was $2.5 \%$, and those who used illicit drugs $3.9 \%$. While $0.7 \%$ of the sample declared the use of cannabinoids, $15.9 \%$ reported alcohol use. In more recent studies, Zaky et al. [12] found the percentage of substance abuse in secondary schools in Menoufiya Governorate to be $15.3 \%$ : tobacco (15.3\%), cannabis (2\%), and benzodiazepines $(0.7 \%)$. Another study [13] done on school and young university male students in Fayoum Governorate showed that cannabis was the commonest substance of abuse (40\%), tramadol (37\%), benzodiazepines (23\%), and parkinol (9\%). The study also found that $62 \%$ of the school students using substances are poly-substance users [13]. A study of substance misuse among preparatory and secondary school students in Assiut Governorate detected the percentage of substance use disorders to be $22.9 \%$ : $50 \%$ in the age group $12-16$ and $49.68 \%$ in the age group $16-19$, with marked male preponderance $(94.59 \%$ males, $5.41 \%$ females). Nicotine was the most frequently used substance (89.9\%), followed by cannabis (5.3\%), beer and alcohol (1.8\%), and tramadol (1.5\%). The prevalence of abuse/dependence was (28.5\%). Occasional and recreational use of drugs was higher (34.63\%) compared to regular use (27.15\%) [14].

The current study aims to reveal the prevalence of substance use and dependence among secondary school students in Egypt. It is meant to describe the true magnitude of the substance abuse problem among Egyptian adolescents, taking into consideration that Egypt has the 16th largest population over the world, the largest Mediterranean population, and the largest Arab population.

\section{Methods}

\section{Selecting the sample}

The population of secondary school students in Egypt ranging between 15 and 19 years old in 2016 was 8,795 , 757 people made up of $4,517,319$ males and $4,278,438$ females which constituted $9.7 \%$ of the total population of 91,023,393 (46,413,993 males and 44,609,400 females). The Egyptian population is distributed over different regions of the country which are the Upper Egypt, the Greater Cairo, and the Lower Egypt Delta. Thus, the geographical regions of the study were selected accordingly to be Cairo, the capital; the Assiut governorate in the region of Upper Egypt, and Al-Menoufiya Governorate in the region of Lower Egypt Delta.

The sample selection was prepared by a committee of experts in statistics and community medicine. They chose three governorates, each representing an Egyptian geographical region. The sample size was calculated for each of the three governorates considering the total number of secondary school students, at $97 \%$ confidence interval and $1.5 \%$ margin of error. A multi-stage sampling procedure was undertaken to ensure proportionate representativeness of different school types (general, industrial, commercial, agricultural, and Azhari) and students' gender. A computer-generated random school selection system was used to include a proportionate sample of schools according to type and gender. In each school, systematic random sampling was followed to select different classes in each school. All students in the selected classes were interviewed (apart from refusals).

A representative sample of the study population was selected from the schools of these governorates. A total number of 320 classes with an average of 13,000 students were targeted in the selected schools during the period between April 3, 2016, and April 24, 2016. From Cairo (the capital), 61 schools were selected (27 general schools, 25 technical schools, and 9 Azhari schools). From Assiut, 34 schools were selected (6 general schools, 22 technical schools, and 6 Azhari schools). And from Al-Menoufiya, 34 schools were selected (8 general schools, 20 technical schools, and 6 Azhari schools). These numbers were arranged to be a representative of the distribution of the population in the designated regions.

\section{Designing the questionnaire}

The questionnaire was prepared by a team of experts in psychiatry, public health, and education. It included questions about socio-demographic details (age, gender, residence, work), questions about family (education, work and marital status of the parents, etc.), the Arabic version of the Strengths and Difficulties Questionnaire (SDQ) [15] and questions about history of medical, psychiatric illnesses or other psychological phenomena, questions adopted from the Addiction Severity Index Scale [16] about the use of substance and its circumstances, and finally questions adopted from Young Internet Addiction Test [17]. The language, understandability, and applicability were tested during the 
pilot study, and a few modifications were performed accordingly.

\section{Pilot study}

The pilot study was conducted in one of the targeted schools in April 2015. Necessary approvals were provided, and informed consents were distributed to the students 3 days before conducting the pilot study questionnaire. Instructions to the "previously trained" researchers were distributed before the data collection. Feedback about the cooperation, the difficulties, and the numbers of participating students, the number of absentees, and the number of parents' refusals was reported. The applicability of the questionnaire was tested. Confusing questions were removed. Questions about different levels of prevalence were rearranged and clarified. The sample of the main study was decided to be at least 11,200 representative students and to yield valid prevalence rates.

\section{Study proper}

Data collection was performed over a 3-week duration from April 3 to April 24, 2016. After getting the informed consents from the caregivers, the students in the selected classes were asked to fill in the questionnaires without writing their names or their school names. The questionnaires were completed under exam/test conditions to guarantee confidentiality. The students were allowed about $30-45 \mathrm{~min}$ to fill in the questionnaire.

\section{Results}

A total number of 13,838 students were approached. On the day of the study, 2392 students were absent, 537 students reported the refusals of their caregivers to participate in the study, and 261 questionnaires were totally unfit for the statistical analysis mostly due to inadequate information. The sample of the study ended to be 10,648 students (4385 males, 6263 females), their ages ranged between 13 and 18 years old.

The students were chosen from three governorates representing the three major regions of the Egyptian territories: Cairo, the capital (45.8\%); Upper Egypt (23.5\%); and Lower Egypt Delta (30.7\%). They also represent the different Egyptian subcultures, i.e., rural (63.3\%), urban (36.1\%), and Bedouin $(0.7 \%)$ cultural backgrounds. A percentage of $17.3 \%$ of the students were working besides their studies (32\% of the male students, $6.8 \%$ of the female students).

The data about family structure showed that the majority of students live within small nuclear families (80.5\%) rather than extended families (18.0\%). A percentage of $17.2 \%$ of the students live in a single-parent family (14.6\% absent father, $2.6 \%$ absent mother), most probably due to traveling parents $(50.9 \%$ traveling father, $45.9 \%$ traveling mother). Family history of substance use reached relatively high levels of nicotine whether cigarettes, water pipe, or e-cigarettes. Female students had a higher family history of cannabis and benzodiazepine use. Cannabis was the most frequently used substance by the families of both male and female students (Table 1).

Among the students, the most commonly used substance was nicotine during lifetime (9\%), last 12 months (4.9\%), and last month (2.4\%) (Table 2). The prevalence was higher among males than among females (Fig. 1). After the exclusion of nicotine, the most frequently used substance during lifetime was benzodiazepines (5.1\%) followed by alcohol (3.3\%) and organic solvents (3.1\%) (Fig. 2). The most used during the last 12 months was alcohol (2.9\%) followed by organic solvents $(2.7 \%)$ and cannabis $(2.6 \%)$. The most used substance during the last month was found to be organic solvents $(1.9 \%)$ followed by benzodiazepines (1.7\%) and alcohol and cannabis with the same rate of use (1.6\%). Ecstasy was found to be a more popular stimulant than cocaine among young people with lifetime prevalence (2.2\%). Figures 3, 4, and 5 show gender difference in the

Table 1 The family history of Substance use

\begin{tabular}{|c|c|c|c|}
\hline & $\begin{array}{l}\text { Male } \\
\text { students (\%) }\end{array}$ & $\begin{array}{l}\text { Female } \\
\text { students (\%) }\end{array}$ & Total (\%) \\
\hline \multicolumn{4}{|l|}{ Nicotine } \\
\hline Cigarettes & 17.6 & 33.5 & 27.2 \\
\hline Shisha & 15 & 22.2 & 19.4 \\
\hline e-cigarettes & 5 & 7.5 & 6.5 \\
\hline \multicolumn{4}{|l|}{ Cannabis } \\
\hline Cannabis & 2.6 & 3.2 & 3 \\
\hline Vodo & 1.2 & 0.4 & 0.7 \\
\hline \multicolumn{4}{|l|}{ Opiates } \\
\hline Tramadol & 1.3 & 1.4 & 1.3 \\
\hline Heroin & 0.8 & 0.3 & 0.5 \\
\hline Morphine/opium & 0.8 & 0.7 & 0.8 \\
\hline Alcohol & 1.5 & 1.8 & 1.7 \\
\hline \multicolumn{4}{|l|}{ Stimulants } \\
\hline Cocaine & 0.6 & 0.2 & 0.4 \\
\hline Ecstasy & 0.7 & 0.3 & 0.5 \\
\hline Hallucinogens & 1 & 0.5 & 0.7 \\
\hline \multicolumn{4}{|l|}{ Psychotropics } \\
\hline $\mathrm{BDZ}$ & 1.7 & 2.3 & 2 \\
\hline Anticholinergic drugs & 0.7 & 0.4 & 0.6 \\
\hline Anabolic steroids & 0.9 & 1.2 & 1.1 \\
\hline Organic solvents & 1.1 & 1.2 & 1.1 \\
\hline
\end{tabular}


Table 2 The prevalence of substance use self-reported by the students

\begin{tabular}{|l|l|c|c|c|}
\hline \multicolumn{5}{|c|}{ PREVALENCES OF SUBSTANCE USE AMONG STUDENTS } \\
\hline \multirow{3}{*}{ Nicotine } & Cigarettes & Last 30 days & Last 12 months & Lifetime \\
\cline { 2 - 5 } & Water pipe & $\mathbf{2 . 4 \%}$ & $\mathbf{4 . 9 \%}$ & $\mathbf{8 . 1 \%}$ \\
\cline { 2 - 5 } & e-cigarettes & $\mathbf{1 . 7} \%$ & $\mathbf{3 . 4 \%}$ & $\mathbf{5 . 5 \%}$ \\
\hline \multirow{3}{*}{ Cannabis } & Cannabis & $0.6 \%$ & $1.1 \%$ & $1.9 \%$ \\
\cline { 2 - 5 } & Vodo & $\mathbf{1 . 6 \%}$ & $\mathbf{2 . 6 \%}$ & $\mathbf{2 . 7 \%}$ \\
\hline \multirow{3}{*}{ Opiates } & Tramadol & $0.8 \%$ & $1.2 \%$ & $1.6 \%$ \\
\cline { 2 - 5 } & Heroin & $0.7 \%$ & $1.4 \%$ & $1.6 \%$ \\
\cline { 2 - 5 } & Opium & $0.4 \%$ & $0.7 \%$ & $1.1 \%$ \\
\hline Alcohol & & $0.7 \%$ & $1.4 \%$ & $1.8 \%$ \\
\hline \multirow{3}{*}{ Stimulants } & Cocaine & $\mathbf{1 . 6 \%}$ & $\mathbf{2 . 9 \%}$ & $\mathbf{3 . 3 \%}$ \\
\cline { 2 - 5 } & Ecstasy & $0.5 \%$ & $0.8 \%$ & $1.1 \%$ \\
\cline { 2 - 5 } & Hallucinogens & $\mathbf{1 . 1 \%}$ & $\mathbf{1 . 7 \%}$ & $\mathbf{2 . 2 \%}$ \\
\hline \multirow{3}{*}{ Psychotropics } & Benzodiazepines & $0.8 \%$ & $1.15 \%$ & $1.4 \%$ \\
\cline { 2 - 5 } & Anticholinergic drugs & $\mathbf{1 . 7 \%}$ & $\mathbf{1 . 7 \%}$ & $\mathbf{5 . 1 \%}$ \\
\hline Anabolic steroids & & $\mathbf{1 \%}$ & $1.4 \%$ & $1.7 \%$ \\
\hline Organic solvents & & $\mathbf{1 . 8 \%}$ & $\mathbf{1 . 7 \%}$ & $\mathbf{2 . 1 \%}$ \\
\hline
\end{tabular}

prevalence of tranquilizer (BDZ) use, alcohol use, and cannabis use.

Among secondary school students, $3.5 \%$ were polysubstance users, $6.3 \%$ of male students and $1.5 \%$ of female students. Most of the poly-substance users were at the age of 16 years old ( $38.4 \%$ of poly-substance users). The prevalence of the regular use of any substance (excluding nicotine) was $1.5 \%$, while the prevalence of the dependence syndrome (excluding nicotine dependence) was $0.9 \%$ (Table 3). Less rates of dependence were detected in Upper Egypt than in Cairo and Delta. The prevalence was higher among males: the "patients" fulfilling the criteria of dependence syndrome constitutes $0.8 \%$ of the total male students and $0.4 \%$ of the total female students.

\section{Discussion}

The age of adolescence is a challenging time. During these ages, youths are making a series of cognitive, biological, psychological, and physiological transitions. Some say that adolescents are "wired" for to seek new experiences and risk-taking. They are in a period where they are trying to find their own identity, looking for peer acceptance, and deal with problems or perform well in school [18]. This makes them more prone to experiment with substances and engage in other harmful behaviors [19]; thus, a plan for prevention should take the adolescents into consideration. Furthermore, the population of the school students is a "well-defined welldelineated" community to an extent. In a Third World country, it is a clearly organized population, in terms of

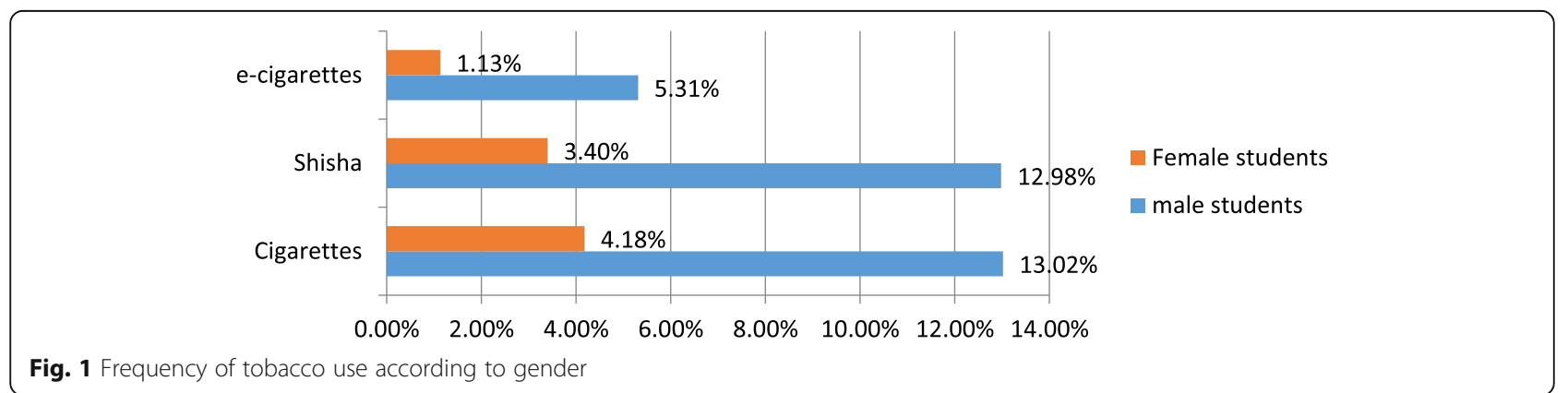




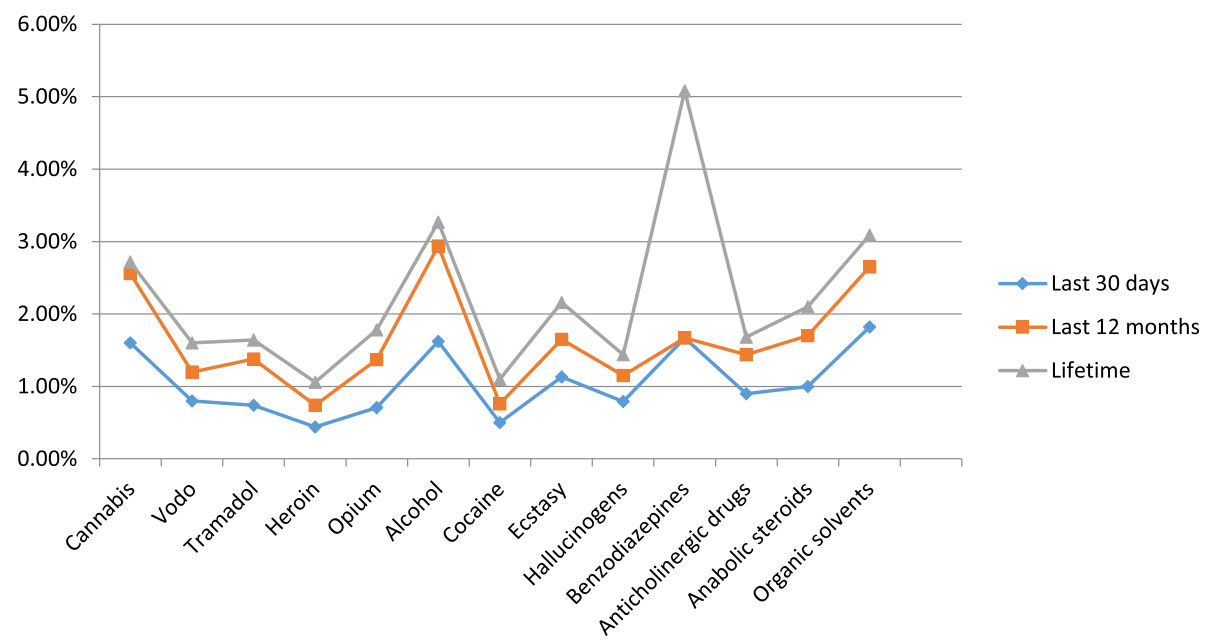

Fig. 2 Self-reported lifetime, last 12 months, and last 30 days prevalence of substance use

geographical distribution, registration, documentation, and caregiver consent. These reasons helped the authors to focus on secondary school students as a target population for the present research.

Generally, the prevalence studies require high standards of representativeness. The sample of the current study was selected and calculated using a multi-stage sampling procedure to ensure proportionate representativeness of different school types and students' gender. Being a sensitive stigmatizing issue, the declaration of using a substance of abuse was encouraged by the structure, the design of the questionnaire, the variable ways of asking repeated questions about substance use in a clear but sensitive manner, and the highest possible confidentiality measures.

The actual sample of the study is 10,648 students (4385 males, 6263 females); their ages are ranging mostly between 13 and 18 years old. In the absence of selection bias, the female preponderance in the sample (58.8\%) challenges the common attitude towards Egyptian female education; UNICEF reports describe higher engagement into education systems in males than in females. Otherwise, a higher representation of female students in the sample may be attributed to the tendency of the male students to absenteeism from school whether for work or for leisure activities. Males are more frequently involved in child labor activities than their female colleagues. The findings point to a percentage of $17.3 \%$ of the students working besides their studies (32\% of the male students, $6.8 \%$ of the female students). The gender differences in child labor may be explained in light of the financial difficulties facing a multitude of Egyptian families, coupled with the universal gender role deeply adopted by many cultures, in addition to an inadequate financial support from the large families, noticed by the low percentage of extended families in comparison with the nuclear family atmosphere (1:4), and the percentage of "single-parent" families, whether due to

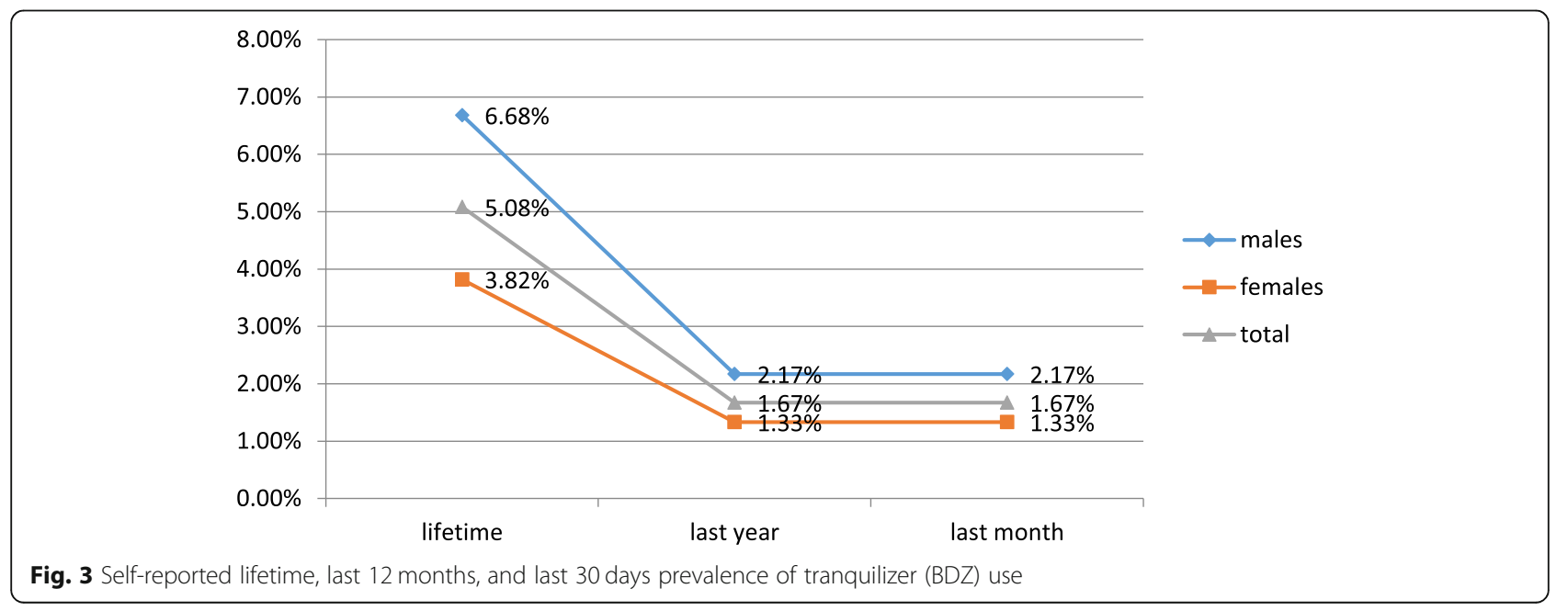




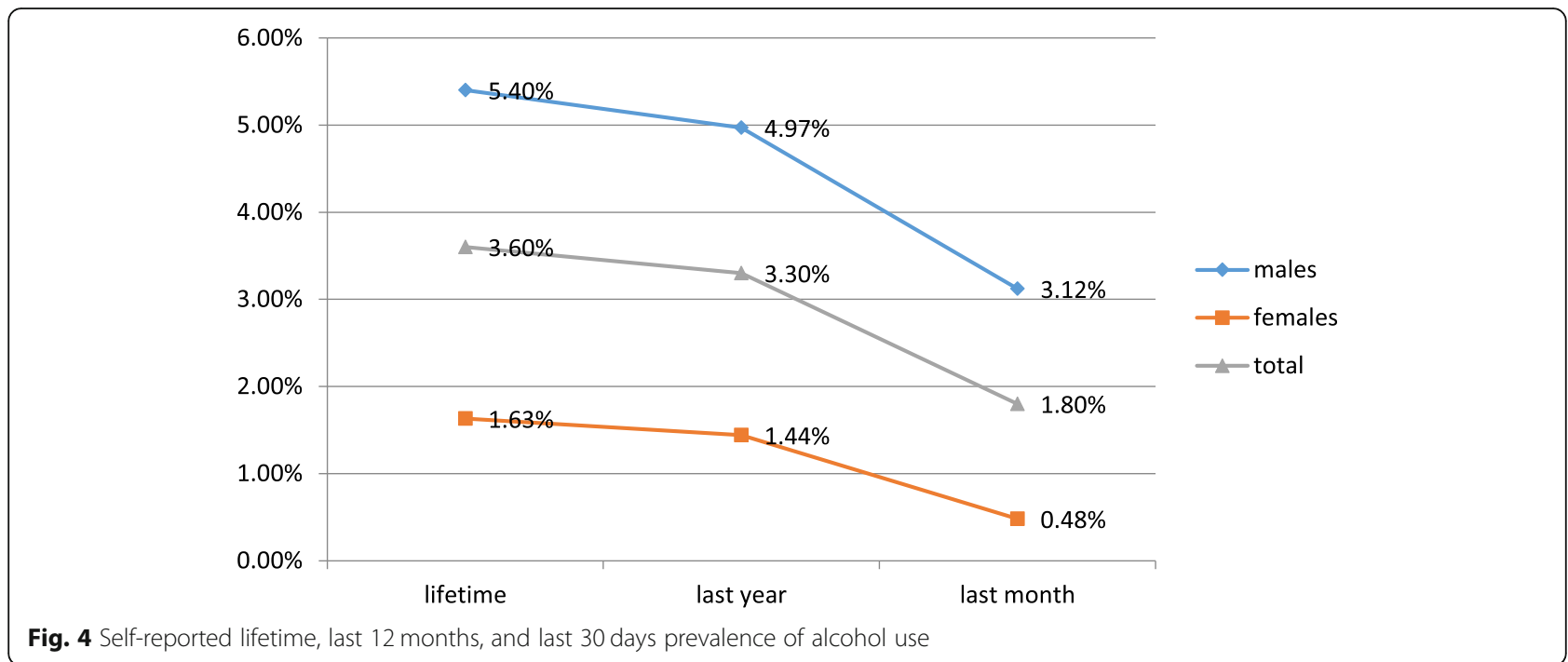

traveling, death of a parent, or parental separation and divorce.

In spite of having a higher family history of nicotine, cannabis, and benzodiazepine use, female students are still less indulged than their male colleagues in polysubstance use $(\mathrm{M}=74.46 \%, \mathrm{~F}=25.54 \%)$ and less fulfilling the criteria of dependence syndrome $(\mathrm{M}=62.1 \%, \mathrm{~F}=$ $37.9 \%)$. This may invite more research about the attitude towards addiction, the perceived dangerousness of substance use, and their relations to the gender and the family history.

In the current study, less rates of dependence are detected in Upper Egypt than in Cairo and Delta. Other studies give conflicting results about the regional distribution of substance use: The last national Egyptian map 2015-2017 showed similar results as regards the prevalence of dependence syndrome: Al-menoufiya 9.3\%, Cairo 6.4\%, and Assiut 3.2\%. However, regarding the rates of substance regular use, National Addiction Research Study revealed the prevalence of use to be $33 \%$ in Cairo, 22.4\% in Upper Egypt, and 9.6\% in Delta [20].

Expectedly, the most commonly used substance in the present research among students was nicotine during lifetime (9\%), last 12 months (4.9\%), and last month (2.4\%). According to the Council of Europe report 2017 on the prevalence of alcohol, tobacco, and drug use among adolescents in the Mediterranean region, the lifetime prevalence of tobacco use was as follows: Italy $58 \%$, France 55\%, Greece 39\%, Portugal 37\%, Cyprus 36\%, Malta 29\%, Tunisia 23\%, Algeria 22\%, Israel 21\%, Morocco 16\%, Lebanon 14\%, and Egypt 9\% [21].

The lifetime prevalence of use of benzodiazepines, e.g., Xanax, apetryl, was the highest among other substances of abuse (5\%) after the exclusion of nicotine, declared by the students. The male use was exceeding the female use, dissonant to the literature stating a female tendency

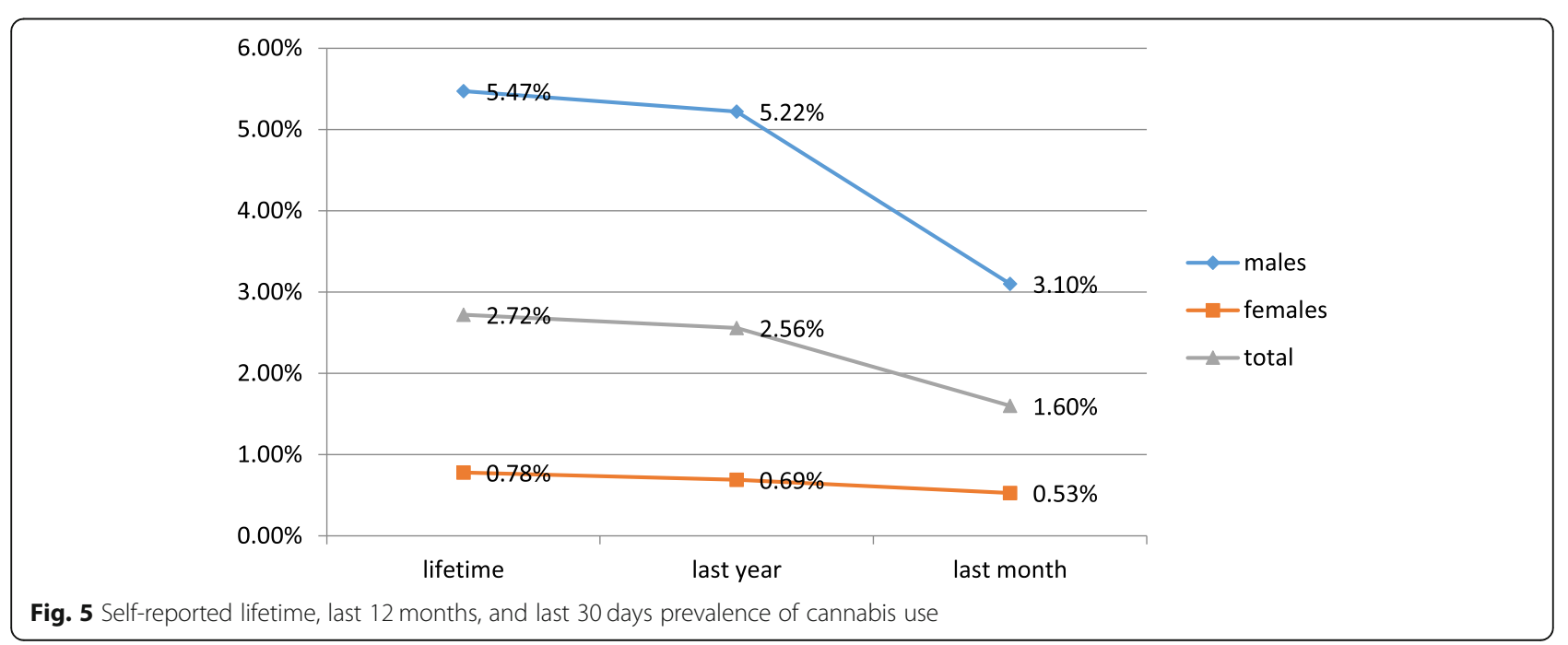


Table 3 DSM-IV dependence syndrome and regular use of substances self-reported by the students

\begin{tabular}{lll}
\hline & Regular use & Dependence syndrome \\
\hline Cannabis & & \\
Cannabis & 0.18 & 0.5 \\
Vodo & 0.17 & 0.27 \\
Opiates & & \\
Tramadol & 0.17 & 0.34 \\
Heroin & 0.05 & 0.10 \\
Opium/morphine & 0.05 & 0.24 \\
Alcohol & 0.12 & 0.42 \\
Stimulants & & \\
Cocaine & 0.05 & 0.17 \\
Ecstasy & 0.09 & 0.20 \\
Hallucinogens & 0.11 & 0.31 \\
Psychotropics & & \\
Benzodiazepines & 0.27 & 0.45 \\
Anticholinergic drugs & 0.06 & 0.24 \\
Anabolic steroids & 0.16 & 0.26 \\
Organic solvents & 0.12 & 0.30 \\
\hline
\end{tabular}

to sleeping pill addiction. Interestingly, the last year and the last month prevalence are quite the same (1.7\%), highlighting that these substances are well tolerated and used regularly (Fig. 3). These findings may be denoting the high levels of anxiety in this special population. The lifetime prevalence of medications without a prescription use among adolescents in the Mediterranean region is almost the same in all countries except France: France $10 \%$, Italy $5 \%$, Portugal 5\%, Morocco 5\%, Cyprus 5\%, Egypt 5\%, Greece 4\%, Algeria 3\%, and Malta 3\% [21]. In the USA, non-medical prescription drug use among youths aged $12-17$ is $2.2 \%$, and non-medical pain reliever use is $1.7 \%$ [22].

In the current study, the lifetime prevalence of alcohol use among students was 3.3\%, with higher estimates among male students than among female students. However, the last month prevalence $(1.6 \%)$ is markedly lower than the lifetime and last year prevalence $(2.9 \%)$, which gives the impression that it is not used regularly and hence not one of the preferred substances (Fig. 4). In comparison with other Mediterranean countries, Egypt had the lowest lifetime prevalence of alcohol use: Greece 94\%, Cyprus 88\%, Malta 86\%, Italy 84\%, France $84 \%$, Portugal $71 \%$, Israel $50 \%$, Lebanon 35\%, Morocco $8 \%$, Algeria 5\%, Tunisia 5\%, and Egypt 3\% [21]. It is obviously observed that other Arab countries had a much lower prevalence of alcohol use than European countries, which can be explained by the cultural and religious differences as alcohol is prohibited by the Islamic religion. In the USA, it was reported that $32 \%$ of 12 th graders, $18 \%$ of 10 th graders, and $6 \%$ of 8 th graders reported being drunk within the last 30 days [3]. Another report showed that approximately $10 \%$ of their sample of youths aged 12-17 met the Diagnostic and Statistical Manual of Mental Disorders-Fourth Edition (DSM-IV) alcohol abuse by self-report, and 3.5\% met the criteria for alcohol dependence [23].

Organic solvents are relatively common in the Egyptian market. It was found to be one of the most common substances used by adolescents of the present study during lifetime (3.1\%, reaching $4.13 \%$ among male students, last 12 months with a prevalence of $2.7 \%$, and the most commonly used in the last 30 days (1.9\%). In the USA, inhalant use within the last 30 days was reported to be $1.2 \%$ for 12 th graders, $2.5 \%$ for 10 th graders, and $3.9 \%$ for 8 th graders showing inhalants to be more favored among younger adolescents [24]. These findings can be attributed to the availability, cheap price, and easy accessibility of organic solvents to this age group.

Expectedly, cannabis (natural and synthetic) was one of the most commonly used substances among the students in the last year (2.6\%) and the last month (1.6\%) prior to the study (Fig. 5). Compared to other Mediterranean countries, the lifetime prevalence of cannabis among Egyptian adolescents was one of the lowest among the region: France 31\%, Italy 27\%, Portugal 15\%, Malta 13\%, Morocco 9\%, Greece 9\%, Israel 8\%, Cyprus $7 \%$, Algeria 5\%, Lebanon 4\%, Egypt $2 \%$, and Tunisia $1 \%$ [21]. In the USA, it was reported that $23 \%$ of 12 th graders, $18 \%$ of 10 th graders, and $8 \%$ of 8 th graders reported using marijuana or other illicit drugs within the last 30 days [3].

According to the Diagnostic and Statistical Manual of Mental Disorders-Fourth Edition (DSM-IV), the prevalence of regular use of any substance (excluding nicotine) among the students of the study was $1.5 \%$, while the prevalence of the dependence syndrome (excluding nicotine dependence) was $0.9 \%$. These rates are lower than those detected in the National Addiction Survey 2015 which was conducted on the Egyptian adult population; most of the sample was from the age group 2635 years old. In this survey, $6.7 \%$ were regular on substance use, while $6.4 \%$ were fulfilling the criteria of dependence. It is obvious that the rates of substance abuse increase by age; thus, preventive services should be mainly directed towards youth in order to combat these phenomena.

\section{Conclusion}

The results of this study attract scientific attention towards the real status of substance abuse problems among adolescents in Egypt. Tobacco is the most 
commonly used substance among secondary school students followed by benzodiazepines which seemed to be used on a regular basis. Alcohol, organic solvents, and cannabis are also commonly used by this population. Although Egypt had the lowest prevalence rates of abuse of these substances among the Mediterranean counties (except for benzodiazepines), preventive measures should be targeting this specific population as the prevalence of substance abuse increases dramatically in the older population.

\section{Abbreviations}

GSMHAT: General Secretariat of Mental Health and Addiction Treatment; $\mathrm{MOH}$ : Ministry Of Health

\section{Acknowledgements \\ Appreciation and gratefulness to Professor Hisham Ramy, Professor of Psychiatry Ain Shams University, for supporting this work. Thanks to all subjects and field researchers who participated in this research and data entry team of the research unit of the GSMHAT, MOH, Cairo, Egypt.}

\section{Authors' contributions}

MR participated in all steps of the study and is the main study coordinator. NMS collected the relevant information, interpreted the results, and wrote the manuscript. EG and ME participated in the preparation of the questionnaire, fieldwork, and data collection. DI participated in designing the study. ME and AL designed the sample and statistical analysis of the collected data. NS and WK participated in the study design and fieldwork. RM supervised the study. All authors read and approved the final manuscript.

\section{Funding}

This research was funded by a grant from the Pompidou Group, Council of Europe, and directed by the General Secretariat of Mental Health and Addiction Treatment (GSMHAT), Ministry of Health (MOH), Cairo, Egypt.

\section{Availability of data and materials}

The datasets used and/or analyzed during the current study are available from the corresponding author on reasonable request.

\section{Ethics approval and consent to participate}

The study protocol was approved by the Ethical Committee of the GSMHAT, $\mathrm{MOH}$. The committee reference number is not applicable; it is the local committee composed of the Head and Deputy Chair of the Research Unit and the Head of Patient's Right Board of the GSMHAT.

A written informed consent was obtained from all the participants after the explanation of the procedures and the objectives of the study.

\section{Consent for publication}

No personal data included in the questionnaire.

\section{Competing interests}

The authors declare that they have no competing interests.

\section{Author details}

${ }^{1}$ General Secretariat of Mental Health and Addiction Treatment (GSMHAT), Ministry of Health (MOH), Cairo, Egypt. ${ }^{2}$ Faculty of Medicine, Ain Shams University, Cairo, Egypt. ${ }^{3}$ Faculty of Medicine, Ain Shams University, Cairo, Egypt. ${ }^{4}$ Department of Biomedical Sciences, University of Malta, Msida, Malta.

Received: 26 September 2019 Accepted: 18 December 2019 Published online: 05 February 2020

\section{References}

1. Gullone E, Moore S (2000) Adolescent risk-taking and the five-factor model of personality. J Adolesc 23(4):393-407

2. Johnston LD, O'Malley PM, Bachman JG, Schulenberg JE (2011) Monitoring the future national survey results on drug use, 1975-2010, volume - secondary school students. Institute for social research, The University of Michigan, Ann Arbor, p 734

3. Peiper NC, Ridenour TA, Hochwalt B, Coyne-Beasley T (2016) Overview on prevalence and recent trends in adolescent substance use and abuse. Child Adolesc Psychiatr Clin N Am 25(3):349-365. https://doi.org/10.1016/j.chc. 2016.03.005

4. Soueif MI, El-Sayed AM, Hannourah MA, Darwish ZA (1979) The non-medical use of psycho-active substances among secondary school male students in Egypt: an epidemiological study (a brief report). Egyptian J Psychiatry 2:198-204

5. Soueif MI, El-Sayed AM, Darweesh ZA, Hannourah MA (1982) The extent of non-medical use of psychoactive substances among secondary school students in Greater Cairo. Drug Alcohol Depend 9:15-41

6. Soueif MI, Youssef GS, Taha HS, Moneim HA, Sree OA, Badr OA, Salakawi M, Yunis FA (1990) Use of psychoactive substances among male secondary school pupils in Egypt: a study on nation-wide representative sample. Drug Alcohol Depend 26:63-79

7. Soueif MI, Yunis FA, Youssef GS, Moneim HA, Taha HS, Sree OA, Badre K (1988) The use of psychoactive substances among the Egyptian male working in manufacturing industries. Drug Alcohol Depend 21:217-229

8. Okasha A, Khalil AH, Fahmy M, Ghanem MH (1990) Psychological understanding of Egyptian heroin users. Egyptian J Psychiatry 13:37-49

9. Demerdash A, Fathi A, El-Tohamy S, Omran S (1992) Substance non-medical use among secondary school students in Assiut city. Egyptian J Psychiatry 15:155-162

10. Hamdi E, Sabry N, Sedrak A, Khowailed A, Loza N, Rabie M, Ramy H (2016, 2016) Sociodemographic indicators for substance use and abuse in Egypt. J Addict Prev 4(1)1-8

11. Sadek A, El-Mahallawy N, Haroun El-Rasheed A et al (2002) Substance use disorders among female secondary school students in Cairo. Egypt J Commun Med 20:4

12. Zaky S, El-Bahnasy R, Mahrous O, Al-Batanony M (2011) Epidemiology of substance abuse among secondary school children- Menoufiya Governorate. MD thesis. Faculty of Medicine, Menoufiya University

13. Mawaheb M, elgalad G, Dawood A, El-Sayed S (2012) Drug abuse among students in schools and colleges in Fayoum City. MD thesis. Faculty of Medicine, Fayoum University

14. Fawzy M, Hassan W, Elbeh K (2012) Prevalence study of psychoactive substance use disorders among students of preparatory and secondary schools in Assiut governorate. MD thesis. Faculty of medicine, Assiut University

15. Alyahri A, Goodman R (2006) Validation of the Arabic Strengths and Difficulties Questionnaire and the Development and Well-Being Assessment. Eastern Mediterr Health J 12(Supplement 2):S138-SS14

16. Qasem T, Beshry Z, Asaad T et al (2003) Profiles of neuropsychological dysfunction in chronic heroine users. M.D. degree thesis. Faculty of Medicine, Ain Shams University

17. Reda M, Rabie M, Mohsen N, Hassan A (2012) Problematic internet users and psychiatric morbidity in a sample of Egyptian adolescents. Psychology vol 3(8):626-631

18. National Institute on Drug Abuse (NIDA) (2016). https://www.drugabuse gov/publications/preventing-drug-use-among-children-and-adolescentsresearch-based-guide/introduction

19. Kande D, Chen K, Warner LA, Kessler R, Grante B (1997) Prevalence and demographic correlates of symptoms of last year dependence on alcohol, nicotine, marijuana and cocaine in the U.S. population. Drug Alcohol Depend 44:11-29

20. Sabry N, Ramy N, Rabie M et al (2018) National addiction survey in Egypt 20152017. $19^{\text {th }}$ EPA-section-Congress Epidemiology\&Social Psychiatry, pp 99-100

21. Muscat R, Molinaro S, Benedetti E (2017) Prevalence of alcohol, tobacco and drug use among adolescents in the Mediterranean Region. MedNet Pompidou Group Website https://www.coe.int/en/web/pompidou/mednet/medspad

22. Nationwide Trends (2016) DrugFacts: http://www.drugabuse.gov/ publications/drugfacts/nationwide-trends

23. Pompili M (2014) Substance abuse and suicide risk among adolescents. Eur Psychiatry 29:1. https://doi.org/10.1016/s0924-9338(14)77664-3

24. Sikes A, Walley C, Mcbride R, Fusco A, Cole RF, Lauka J (2011) Inhalant and prescription medication abuse among adolescents: an inexpensive, accessible, and misperceived trend. J Child Adolesc Subst Abuse 20(3):237252. https://doi.org/10.1080/1067828x.2011.581903

\section{Publisher's Note}

Springer Nature remains neutral with regard to jurisdictional claims in published maps and institutional affiliations. 